Nazroo, J. (1997) Ethnicity and Mental Health. London: PSI. Putnam, R. D. (2000) Bowling Alone: The Collapse and Revival of American Community. New York: Touchstone.

Selten, J. P., Slaets, J. P. \& Kahn, R. S. (1997) Schizophrenia in Surinamese and Dutch Antillean immigrants to The Netherlands: evidence of an increased incidence. Psychological Medicine, 27, 807-811.

Silove, D., Steel, Z. \& Watters, C. (2000) Policies of deterrence and the mental health of asylum seekers. JAMA, 284, 604611.

Stalker, P. (1994) The Work of Strangers. London: International Labour Organization.

Stiglitz, J. (2002) Globalization and its Discontents. London: Penguin.

Torrey, E. F. (2001) Surviving Schizophrenia. New York: HarperCollins.

United Nations (1991) Principles for the Protection of Persons with Mental Illnesses and the Improvement of Mental Health Care. New York: United Nations.

Wiersma, D., Giel, R., De Jong, A., et al (1983) Social class and schizophrenia in a Dutch cohort. Psychological Medicine, 13, 141-150.

World Bank (2001) World Development Report 2000/2001. New York: Oxford University Press.

World Psychiatric Association (2002) Draft Core Curriculum. http://www.wpanet.org/sectorial/docs/draft $\% 20$ core $\%$ curriculum.zip)

\section{Multiple choice questions}

1 In relation to migration:

a 5 million people emigrate permanently each month

b 1 million people seek asylum abroad each year

c migration has reduced in recent years

d 1.5 million people emigrate permanently each year

e migration is not a key feature of globalisation.

2 In relation to migration and health:

a migration is related to risk of mental illness

b migration improves physical health

c asylum-seekers rarely present with post-traumatic stress disorder

d migrants have higher rates of involuntary admission than native populations

e schizophrenia is less common in migrants than in native populations.
3 The United Nations' Principles for the Protection of Persons with Mental Illness:

a were introduced by the World Health Organization

b date from the 20th century

c have the status of a formal international treaty

d provide a framework for legislative change in individual countries

e could usefully inform programmes of psychiatric education.

4 Following the events of 11 September 2001 in the USA:

a the prevalence of post-traumatic stress disorder in Manhattan increased

b the prevalence of depression in Manhattan increased

c psychopathology was unrelated to Hispanic ethnicity

d psychopathology was related to pre-existing social ties

e commentators began to re-evaluate policies related to globalisation.

5 The concept of anomie:

a was introduced by Putnam

$\mathrm{b}$ is unrelated to suicide

c relates to the belief that aliens are taking over the earth

$\mathrm{d}$ is related to psychosocial distress in times of change

e has added significance in the context of globalisation.

\begin{tabular}{|c|c|c|c|c|}
\hline 1 & 2 & 3 & & 4 \\
\hline $\mathrm{F}$ & a $\mathrm{T}$ & & $\mathrm{F}$ & a $\mathrm{T}$ \\
\hline $\mathrm{T}$ & $\mathrm{b} F$ & & $\mathrm{~T}$ & b $\mathrm{T}$ \\
\hline $\mathrm{F}$ & c F & & $\mathrm{F}$ & c F \\
\hline $\mathrm{T}$ & $\mathrm{d} \mathrm{T}$ & & $\mathrm{T}$ & $\mathrm{d} T$ \\
\hline F & e F & & $\mathrm{T}$ & e $\mathrm{T}$ \\
\hline
\end{tabular}

\title{
INVITED COMMENTARY ON Globalisation and psychiatry
}

Dr Kelly's paper (Kelly, 2003, this issue) is a timely review of the effect of globalisation on mental health and its impact on psychiatric services and of the role that psychiatrists and their professional organisations can play in responding to this phenomenon.
Globalisation, defined by Kelly as 'crossing borders', is, as he points out, not a new phenomenon. Indeed, peoples have moved around the world, probably since time immemorial, and one need look no further than the Bible for confirmation that many of the reasons for these movements were 
the same then, millennia ago, as they are today: economic, to seek a better way of life and a higher standard of living (economic migrants); fleeing conflict and persecution (asylum-seekers); and to conquer and colonise. Nor is it only people that have moved across borders. Trade has been international for many centuries, imbued with the romanticism of the Silk Road, the Spice Islands and the tea clippers.

\section{Why is globalisation so important?}

So what is so different today, that globalisation is now thought to be important enough to warrant conferences and learned papers? And, specifically, what is its impact on mental health and the consequent role of psychiatry?

The perceived problems of globalisation are related to a number of different factors.

\section{The magnitude and speed of migration}

First, there is the combination of scale, speed and distance of migration. This now results in influxes of large numbers of people into distant and often very different cultures. The consequent cultural diversity can justifiably be lauded as enriching, but in practice it can be very difficult for the individuals concerned - both the immigrants and the indigenous population - to cope with. Such differences are often accentuated by the comparative poverty of immigrant communities. Traditionally, immigrants have arrived with little or nothing and, although they might have had high social and educational status in their own countries, often they have no choice but to undertake poorly paid, menial labour in the receiving country. This can be an immensely stressful experience for these individuals, who find themselves on the wrong side of a socio-economic divide in a strange and often unwelcoming country. It is important also to acknowledge that the sudden arrival of a large number of people who are perceived as competing for limited resources (benefits, housing, education, health care) can be worrying and it is unfair to dismiss such anxieties as racism.

\section{Global trade}

In contrast to migration, which in its essentials has changed little over the centuries, global trade, in its broadest sense, has changed dramatically, not just quantitatively but qualitatively because of the growth in the number and size of multinational corporations. This has resulted in a worldwide homogeneity of consumer goods and brand names that appears to threaten local traditions. Simultaneously, it has become evident that the real increase in international wealth has not been equally distributed and that some countries are now vastly wealthier than others (World Bank, 2001). Among many possible examples of such inequalities, the following are particularly striking:

- the wealth of the world's three richest billionaires exceeds the combined assets of the 600 million people in the world's poorest countries (Sacks, 2003);

- Americans spend more on cosmetics, and Europeans on ice cream, than it would cost to provide sanitation and schooling for the two billion people who currently go without (Sacks, 2003);

- 10 countries account for more than $80 \%$ of global analgesic morphine consumption, and more than 120 countries report little or no opioid analgesic consumption (Ghodse, 2003).

\section{Information technologies}

In theory, information technologies could and should help to narrow this gap; as Kelly points out, they are spreading rapidly from developed to developing countries and they are enabling and empowering (Mandil, 1998; Sharma, 2000). But there is also a risk that the current 'digital divide' will increase inequalities, with wealthy economies utilising new technologies to speed even further away from those at subsistence level.

\section{Inequalities: acknowledging and redressing}

These inequalities between nations are relevant to this discussion because of their acknowledged effect on health in general and on mental health in particular (Saraceno \& Barbui, 1997; World Health Organization, 2001). And a significant difference now is that the world knows about the inequalities. Globalisation of communication, in all its diverse forms, means that people in rich countries do know of others' poverty. More significantly, it also means that those in poor countries know what they are missing; they know that people are better off elsewhere. And combined with this painful knowledge there is often an inability to do much about it, partly because the world's international monetary systems do not favour weak economies and partly because the commercial decisions of huge multinational companies, in terms of movement of money and shifts of production, can work against governments' policy decisions anyway. Small wonder that such powerlessness 
generates anger, frustration and mental ill health, which are at risk of being channelled, often via the new information technologies, into powerful and violent responses that threaten national and international security (Global Forum for Health Research, 2002).

\section{Effects on psychiatry}

What then of psychiatry? What role can psychiatrists play in ameliorating the current position? Clearly, they cannot alone rectify the mental health problems associated with globalisation, but their unique knowledge and skills can be used to make a valuable contribution in many areas. For example, with their well-honed communication skills, they should be leading the way in facilitating and enhancing communication between immigrants and others in their local community, developing an environment in which diversity and difference are acknowledged, respected and cherished.

\section{Displacement is a global problem}

Psychiatrists need to be prepared to treat the higher rates of mental illness that occur in the immigrant population (Bhugra \& Jones, 2001; Gavin et al, 2001). This preparation must include adequate education and training, so that the particular cultural features of mental illness in specific populations are fully taken into account. Kelly's paper explores a number of such issues, but adopts a somewhat Eurocentric/UK-centric stance. In the face of frequent headlines about the number of asylum-seekers and targets for their reduction, it is easy to forget that the number of immigrants from, say, Afghanistan to the UK is a tiny fraction of the number crossing the land borders into neighbouring Iran and Pakistan. Those millions of people might not have travelled so far, but they too have given up their homes, their possessions and their jobs, then to live in comparative squalor in refugee camps. They too will be stressed and unhappy and have higher rates of mental illness, but in a situation in which there are far fewer resources with which to treat them - and because such patients generate few scientific papers, they tend to be overlooked in accounts of globalisation and mental health.

\section{International collaboration}

Another role for psychiatrists, therefore, is to develop a dialogue with colleagues who might be dealing with similar issues in very different circumstances. The increased speed of communication that has developed as part of the globalisation process will facilitate this dialogue, but it must be a true dialogue, that acknowledges contributions from all participants and provides a learning environment for all. A well-intentioned willingness to share the knowledge and educational courses developed in the West should not become a patronising attempt to impose the findings and practices of industrialised countries on those working in very different situations. Part of the solution might be to use to the full the knowledge and experience of mental health professionals who are part of the immigrant community and to remove some of the barriers to their professional integration.

\section{Human rights}

Finally, of course, there is the role of psychiatry in human rights issues. In the past, most attention has been paid to the treatment of victims of torture and also to the abuse of psychiatry for political purposes. What has been lacking is a willingness to expose gross socio-economic inequalities, to explain how they lead to ill health, and specifically to mental ill health, and how this, in turn, is a fertile breeding ground for terrorism.

\section{Conclusion}

In summary, as Kelly's article demonstrates, the impact of globalisation on mental health and mental health services is complex. Although globalisation offers enhanced opportunities for sharing knowledge and improving treatment, there is a real risk that it will further widen the existing gap between rich and poor, with adverse effects on mental and physical health. The role of psychiatry in advocacy for the most deprived has not been fully developed.

\section{References}

Bhugra, D. \& Jones, P. (2001) Migration and mental illness. Advances in Psychiatric Treatment, 7, 216-223.

Gavin, B. E., Kelly, B. D., Lane, A., et al (2001) The mental health of migrants. Irish Medical Journal, 94, 229-230.

Ghodse, H. (2003) Pain, anxiety and insomnia - a global perspective on the relief of suffering. Comparative review. British Journal of Psychiatry, 183, 15-21.

Global Forum for Health Research (2002) Health Research, Health, Development, Poverty and Global Security. The 10/90 Report on Health Research 2001-2002. Geneva: World Health Organization.

Kelly, B. D. (2003) Globalisation and psychiatry. Advances in Psychiatric Treatment, 9, 464-470.

Mandil, S. (1998) Telehealth: what is it? Will it propel crossborder trade in health services? In International Trade in Health Services: A Development Perspective (ed. S. Zarrilli). Geneva: United Nations \& World Health Organization. 
Sacks, J. (2003) The Dignity of Difference (2nd edn). London: Continuum.

Saraceno, B. \& Barbui, C. (1997) Poverty and mental illness. Canadian Journal of Psychiatry, 42, 285-290.

Sharma, D. C. (2000) Remote Indian villages to benefit from telemedicine project. Lancet, 355, 1529.

World Bank (2001) World Development Report 2000/2001. New York: Oxford University Press.
World Health Organization (2001) World Health Report. Mental Health: New Understanding, New Hope. Geneva: WHO.

A. Hamid Ghodse Professor of Addictive Behaviour and Psychological Medicine, St George's Hospital Medical School, Cranmer Terrace, London SW17 0RE, UK.

\section{INVITED COMMENTARY ON Globalisation and psychiatry}

The responses of nations and individuals to globalisation and the effects of the phenomenon on the mental health of the population are many and varied, according to its critics' perceptions. Kelly (2003, this issue) highlights the greatest criticism of globalisation - the management of cultural diversity. This is related to homogenisation of cultures across the globe and to how that process leads to loss of individual and kinship cultural identities. The act of globalisation is based simply on a capitalist mode of production - moving it around the world to use cheap labour - and on increased access to global media. Both of these influence cultures in the context of industrialisation and urbanisation. Berger (2002) suggests that the dynamics of globalisation are related to diffusion of culture through both elite and popular vehicles: business and the media.

Kelly argues for a return to the biopsychosocial model of psychiatry, and he is right. However, biopsychosocial models never went away - only the biosocial psychiatrists did, in their rush to identify genes leading to schizophrenia or to study brain scans to identify areas that contribute to mental illness. Unfortunately, neither pathway has led to a psychiatric utopia. Today, the social has given way to cultural, spiritual and anthropological aspects of new aetiological models trying to enter the nosology.

\section{Migration in the era of globalisation}

Globalisation not only leads to migration of individuals across national boundaries: the borders themselves are 'disappearing' because of the internet. Globalisation is seen as the intensification of global interconnectedness (Inda \& Rosaldo, 2002).
This leads to an itinerant capitalism that demands the cheap production of goods, which in turn results in the industrialisation of nations that have the workforce but not the infrastructure to cope with it. The consequent rural-to-urban migration brings with it a series of problems and expectations. Blue et al (1995) have elegantly demonstrated increased rates of common mental disorders in the urban slums of India, Brazil and Chile. This increase is related to social factors - poor housing and its related infrastructure and economic problems. The loss of social support resulting from migration to urban areas brings its own problems.

There is considerable evidence to suggest that migrants are prone to particular psychiatric illnesses (Bhugra 2001; Bhugra \& Jones, 2001). The acculturation due to globalisation may lead to loss of original cultural identity, thereby giving rise to certain psychiatric conditions.

We know that 'culture shock' and conflict of cultures also lead to increased psychological morbidity. Kelly places poverty at the top of the list for increase in morbidity, but increasing awareness of discrepancy between what individuals thought that they could achieve as a direct or indirect result of globalisation and what they actually attain is more likely to produce alienation and hopelessness.

\section{Urbanisation and industrialisation}

The urbanisation and industrialisation arising from globalisation both lead to a loss of personal identity. The individual and cultural voice of the 'other' expected to provide the labour of globalised industry is lost. Gupta \& Ferguson (2002) enquire about the identity of the 'we' as well as of the 'other'. A cultural 